\title{
Zinc Finger and BTB Domain-Containing Protein 7B
}

National Cancer Institute

\section{Source}

National Cancer Institute. Zinc Finger and BTB Domain-Containing Protein 7B. NCI

Thesaurus. Code C150354.

Zinc finger and BTB domain-containing protein 7B (539 aa, $\sim 58 \mathrm{kDa}$ ) is encoded by the human ZBTB7B gene. This protein plays a role in the regulation of both $\mathrm{T}$-cell differentiation and collagen gene expression. 